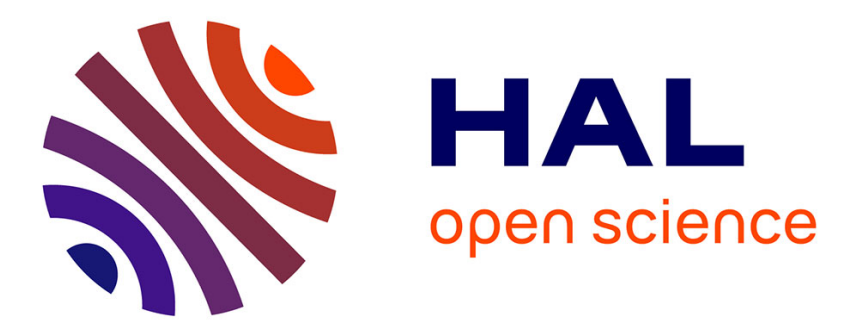

\title{
AcpA, a member of the GPR1/FUN34/YaaH membrane protein family, is essential for acetate permease activity in the hyphal fungus Aspergillus nidulans
}

Xavier Robellet, Michel Flipphi, Sylvine Pégot, Andrew P Maccabe, Christian Vélot

\section{To cite this version:}

Xavier Robellet, Michel Flipphi, Sylvine Pégot, Andrew P Maccabe, Christian Vélot. AcpA, a member of the GPR1/FUN34/YaaH membrane protein family, is essential for acetate permease activity in the hyphal fungus Aspergillus nidulans. Biochemical Journal, 2008, 412 (3), pp.485-493. 10.1042/BJ20080124 . hal-00478955

\section{HAL Id: hal-00478955 https://hal.science/hal-00478955}

Submitted on 30 Apr 2010

HAL is a multi-disciplinary open access archive for the deposit and dissemination of scientific research documents, whether they are published or not. The documents may come from teaching and research institutions in France or abroad, or from public or private research centers.
L'archive ouverte pluridisciplinaire HAL, est destinée au dépôt et à la diffusion de documents scientifiques de niveau recherche, publiés ou non, émanant des établissements d'enseignement et de recherche français ou étrangers, des laboratoires publics ou privés. 


\title{
AcpA, a member of the GPR1/FUN34/YaaH membrane protein
}

\section{family, is essential for acetate permease activity in the hyphal fungus Aspergillus nidulans}

\author{
Xavier Robellet $^{1}$, Michel Flipphi ${ }^{2}$, Sylvine Pégot ${ }^{1}$, Andrew P. MacCabe ${ }^{2}$ \\ and Christian Vélot ${ }^{{ }^{*}}$
}

From the ${ }^{1}$ Institut de Génétique et Microbiologie, Unité Mixte de Recherche 8621, CNRS - Université Paris-Sud XI, Centre Scientique d'Orsay, Bâtiment 360, F-91405 Orsay Cedex, France,

and the ${ }^{2}$ Instituto de Agroquímica y Tecnología de Alimentos, Consejo Superior de Investigaciones Científicas, Apartado de Correos 73, 46100 Burjassot, Valencia, Spain Running Title : Acetate permease in Aspergillus nidulans

Address correspondence to: Christian Vélot, IGM, Centre Scientifique d'Orsay, Bât. 360, 91405 Orsay Cedex. E-mail: christian.velot@igmors.u-psud.fr, Tel.: (33) 16915 82 95, Fax: (33) 169156334.

Keywords: Monocarboxylate transport, acetate, Aspergillus nidulans, GPR1/FUN34/YaaH protein family, gene expression 


\section{ABSTRACT}

In a previous study, alcS, a gene of the Aspergillus nidulans alc cluster, was shown to encode a protein that belongs to the GPR1/FUN34/YaaH membrane protein family. BLAST screening of the $A$. nidulans genome data identified additional genes encoding hypothetical proteins that could belong to this family. In this study we report the functional characterization of one of them, AN5226. Its expression is induced by ethanol and ethylacetate (two inducers of the alc genes) and is mediated by the specific transcriptional activator of genes of the acetate-utilization pathway FacB. Growth of a null mutant ( $\triangle A N 5226)$ is notably affected when acetate is used as sole carbon source at low concentration and in a high $\mathrm{pH}$ medium, i.e. when protonated acetate, the form that can enter the cell by passive diffusion, is present in low amounts. Consistently, expression of $A N 5226$ is also induced by acetate, but only when the latter is present at low concentrations. ${ }^{14} \mathrm{C}$-Acetate uptake experiments using germinating conidia demonstrate an essential role for AN5226 in mediated acetate transport. To our knowledge this report is the first to provide evidence for the identification of an acetate transporter in filamentous fungi. We have designated AN5226 as acpA (for acetate permease). 


\section{INTRODUCTION}

Like other filamentous fungi, Aspergillus nidulans is able to grow on two-carbon compounds, such as acetate and ethanol, as sole carbon sources. The ethanol utilization pathway of $A$. nidulans (termed the alc system) requires two structural genes, alc $A$ and ald $A$. These encode the enzymes alcohol dehydrogenase and aldehyde dehydrogenase, respectively, which catalyse the conversion of ethanol into acetate via acetaldehyde. Induction of alcA and ald $A$ expression is controlled by a regulatory gene, alcR, encoding the pathway-specific autoregulated transcriptional activator [1]. To enter mainstream metabolism, acetate is further converted into acetyl-CoA by acetyl-CoA synthetase, encoded by $f a c A[2,3]$. Acetyl-CoA is either catabolized by the Krebs tricarboxylic acid (TCA) cycle in the mitochondrion or assimilated by the glyoxylate cycle, an anaplerotic version of the TCA cycle that is absolutely required for the utilization of two-carbon compounds when they are present as sole carbon sources. The glyoxylate pathway, present in bacteria, plants and fungi, enables the synthesis of C4 dicarboxylic acids from acetyl-CoA units, bypassing the two decarboxylation steps in the TCA cycle. The C4 metabolites so produced can be used for energy production, gluconeogenesis and other biosynthetic pathways. In A. nidulans, the two enzymatic activities specific to the glyoxylate cycle, isocitrate lyase and malate synthase, are encoded by $a c u D[4]$ and $a c u E[2,3]$, respectively. Unlike alcA, aldA and $a l c R$, the $a c u D, a c u E$ and $f a c A$ genes are under the control of $\mathrm{FacB}[3,5]$, the acetate utilization pathway-specific transcriptional activator.

alcR and alcA are clustered on the left arm of chromosome VII together with three other genes, alcO, alcM and alcS, that are subject to strict AlcR control [6]. However, their functions remain unknown. In a previous study [7] we showed that alcS encodes a plasma membrane protein belonging to the GPR1/FUN34/YaaH family which includes among others, Gpr1p of Yarrowia lipolytica [8] and Ady2p and Fun34p of Saccharomyces cerevisiae [9, 10]. While no clear biochemical function has yet been established for any protein in this family (Transporter Classification system: TC-9.B.33), phenotypic effects have been described in yeast species for gprl and $a d y 2$ mutants in relation to the utilization of acetate as the growth substrate. In S. cerevisiae, ADY2 expression (as well as that of FUN34) is elevated in liquid culture upon a shift from glucose medium to the non-fermentative growth substrate acetate. Deletion of $A D Y 2$ results in the loss of mediated acetate uptake, implying that this gene is necessary for the expression of an acetate permease [11]. In Y. lipolytica, deletion of the GPRI gene leads to a prolonged lag phase in growth on acetate [12]. Moreover, a recent study shows that certain mutations in $A D Y 2$ and FUN34 likewise induce acetic acid 
sensitivity in $S$. cerevisiae [13]. By contrast, $A$. nidulans alc $S$-deleted mutants do not display any obvious phenotype (on ethanol nor on acetate), suggesting that some other gene/genes might be able to compensate the absence of alcS under the conditions tested. A BLAST search of the A. nidulans genome [14] led to the identification of two novel genes that are induced by ethanol and ethylacetate (inducers of the alc system) and that could encode other members of the GPR1/FUN34/yaaH family, AN5226 and AN8390 [7].

Here we report the functional characterization of AN5226, now designated AcpA (for acetate permease A). An acpA gene deletion mutant shows notably reduced growth when acetate is used as a sole carbon source at low concentration and in a high $\mathrm{pH}$ medium. ${ }^{14} \mathrm{C}$ Acetate uptake experiments using germinating conidia lead us to identify AcpA as an essential component of mediated acetate transport.

\section{EXPERIMENTAL}

Strains, media, general growth conditions: The A. nidulans strains used in this study are listed in Table 1. Genotypic annotations have been described previously [15]. Media composition, supplements and basic growth conditions were as described by Cove [16]. Nitrogen sources were generally added to a final concentration of $10 \mathrm{mM}$ nitrogen, i.e. diammonium tartrate and urea were each used at $5 \mathrm{mM}$. Carbon sources were added at either $0.1 \%, 0.5 \%$ or $1 \%(\mathrm{w} / \mathrm{v}$ or $\mathrm{v} / \mathrm{v})$ as specified

General molecular techniques, classical genetics, transformation: Standard molecular techniques were as described in Sambrook and Russell [17]. Aspergillus genomic DNA utilized for PCR reactions and in Southern blot analyses was isolated according to Specht et al. [18]. PCR products were purified using the High Pure PCR Product Purification Kit (Roche). Auxotrophic markers were exchanged and mutant alleles were combined through meiotic recombination employing conventional genetic techniques [19]. Protoplast generation and transformation of $A$. nidulans with PCR-amplified DNA were performed essentially as described by Tilburn et al. [20].

Structure of the acpA gene: Features of the acpA gene structure (intron positions, transcription start- and end-points) were revealed upon sequencing of cDNA clones obtained upon rapid amplification of cDNA ends (RACE) with a sample of total RNA. The RACE of acp $A$ was performed with RNA isolated (according to the method described below) from a $\Delta$ alcS strain (CV171) induced with ethylacetate, utilizing a number of gene-specific oligonucleotide primers (Table 2). The GeneRacer kit from Invitrogen was used for the 5' RACE and the 5'/3' RACE kit $2^{\text {nd }}$ generation from Roche was used for the 3' RACE. 
Construction of the acpA::panB disruption cassette: A gene replacement strategy, based on the principle of double joint PCR [21], was designed to obtain acpA complete loss-of-function mutants. The 5' and 3' flanking sequences of acpA were amplified using the oligonucleotide couples 5226-5' anti/5226-5' -pto3'-sht and 5226-3'sens/5226-3'-pto5'-sht (Table 2). The oligonucleotides 5226-5'-pto3'-sht and 5226-3'-pto5'-sht have 28 and 30 base-long homologies with the 3 ' and 5' non-coding regions of the ketopantoate hydroxymethyl transferase $(p a n B)$ gene [22], respectively. Genomic DNA from strain BF107 was used as the template for PCR amplifications of the 5' and 3' acpA flanking regions. The panB gene was amplified using the oligonucleotide couple pto3'-5226-5'sht/pto5'-5226-3'sht (Table 2). These oligonucleotides have 28-29 base-long homology with the 5' and 3' non-coding regions of the acpA gene. The plasmid pJVF089 carrying a functional $A$. nidulans panB gene [23] was used as the template for this PCR. After gel purification, equimolar amounts of the three fragments obtained were fused by means of a PCR without oligonucleotide primers under the following conditions: $5 \mathrm{~min}$ at $94^{\circ} \mathrm{C} ; 15$ cycles of $\left(45 \mathrm{~s}\right.$ at $94^{\circ} \mathrm{C}, 2 \mathrm{~min}$ at $58^{\circ} \mathrm{C}$ and $8 \mathrm{~min}$ at $68^{\circ} \mathrm{C}$ ) and $15 \mathrm{~min}$ post-polymerisation with the Expand Long Template PCR System (Roche). Subsequently, the oligonucleotide couple 5226-5'anti/5226-3'sens were added and the same cycling program was executed except that the number of cycles was increased to 25 . Finally, a PCR was performed with nested oligonucleotides, Nes5226-3'sens and Nes5226-5' anti (Table 2), to generate the acpA::panB disruption cassette $(\sim 6.5 \mathrm{~kb})$.

Generation of the null $\triangle \mathrm{acpA}$ and the double $\triangle \mathrm{acpA} \triangle \mathrm{alcS}$ mutants: To generate the acp $A$ knock-out mutant, $3 \mu \mathrm{g}$ of the 6.5-kb acpA disruption cassette (see above) was used to transform the D-pantothenic acid-requiring panB100 strain CV164 and the $\Delta a l c S$ panB100 strain CV171 (Table 1). Disruption of the $a c p A$ gene in a number of pantothenate prototrophic transformants was checked by Southern analysis. The resulting null $\triangle a c p A$ and the double $\triangle a c p A \Delta a l c S$ mutant strains used in this study were termed CV260 and CV253 (Table 1). CV164 and CV171 were also transformed with the 2.5-kb panB fragment alone to generate the control strains CV312 and CV313 (i.e., pantothenate prototrophic transformants carrying a wild-type acpA gene - see Table 1).

Transcript analysis: Mycelia for transcript analysis were grown for $24 \mathrm{~h}$ in appropriately supplemented minimal medium with lactose $(3 \% \mathrm{w} / \mathrm{v})$ as the carbon source and urea as the nitrogen source [24]. Media were buffered with $100 \mathrm{mM}$ sodium phosphate $\mathrm{pH} 6.8$ added to cooled autoclaved medium from filter-sterilized stocks. Induction was achieved by the addition of the inducers to the concentrations indicated and cultures were harvested after $2.5 \mathrm{~h}$ of further incubation. Total RNA was isolated from mycelia as described previously [25]. 
Northern analysis was carried out with $10 \mu \mathrm{g}$ samples of glyoxal-treated total RNA essentially as dscribed by Flipphi et al. [25]. DNA probes were labelled with ${ }^{32} \mathrm{P}$ dCTP using the Megaprime $^{\mathrm{TM}}$ DNA Labelling System (Amersham Biosciences). Hybridisation signals were revealed using a PhosphorImager (Molecular Dynamics). The $\gamma$-actin (acnA) gene served as a reference as it is considered to be expressed equally well in all strains and under all conditions tested.

Acetate uptake measurements: The isolation of germinating conidia and uptake measurements were performed essentially as previously described by MacCabe et al. [26]. Acetate uptake rates were measured by assaying the incorporation of $\left[1-{ }^{14} \mathrm{C}\right]$ acetic acid (sodium salt, with a specific activity of $2.11 \mathrm{GBq} / \mathrm{mmol}$; GE Healthcare) into conidia at various external acetate concentrations. Uptake was quenched by rapid addition of $1.5 \mathrm{ml}$ icecold unlabelled $1 \mathrm{M}$ acetate in minimal medium at $\mathrm{pH}$ 6.8. The nitrocellulose filters used to collect the germinating conidia were rinsed with $1.5 \mathrm{ml}$ of the same acetate solution immediately prior to sample filtration. Acetate uptake rates were determined by linear regression of plots of the amounts of radiolabelled acetate taken up by a fixed number of 4-h old glucose germlings after short periods of incubation (i.e. 5, 30, 60, 90, 120 and 180 seconds) at $37^{\circ} \mathrm{C}$ in a fixed volume under continuous agitation. All data were analysed using SigmaPlot Version 8.02 (SSP Inc.)

\section{RESULTS}

Structure of the acpA gene and its putative translation product

Using RACE, the exact position of the $a c p A$ transcripts was mapped by analyzing the sequences of a number of $a c p A$-specific cDNA clones generated from the same RNA sample obtained from ethylacetate-induced mycelium (see Experimental). The acp $A$ open reading frame (ORF) and its flanking regions is shown in Fig. $1 A$. The complete DNA sequence determined is available under the GenBank accession number EF428327. Sequencing of the acp $A$-cDNA identified two intron sequences disrupting the coding region of the gene. The coding sequence formed upon their removal would encode a putative product of 298 amino acids. Consistent with the two acpA RNA products observed on northern blots [7], 5'-RACE experiments identified two 5' untranslated regions (5' UTR) of 398 and 247 bases in length. However, the two transcriptional initiation sites are 469 bases apart. This discrepancy is due to the absence of a 318 base sequence in the 5' UTR of the longer transcript running from position -339 to position -22 (relative to the presumed start codon) (Fig. 1A and $1 B$ ). This upstream intron sequence exhibits an unusual structure, in particular towards its 3 ' end, where 
it is heavily enriched in adenine residues organized in consecutive polyA stretches located between a 216 base ORF found within the intron and the presumed intron lariat sequence (GCUGAC). The transcription initiation site of the shorter RNA product is located within this 5' UTR intron (Fig. $1 A$ and $1 B$ ) hence the 5' UTR sequence is almost unique for each of the two transcripts, with the exception of the 21 bases immediately preceding the presumed start codon. To confirm the data obtained from these 5'-RACE experiments, we probed a northern blot made with total RNA isolated from ethylacetate-induced mycelia using probes specific for each of the acpA mRNA products (Fig. 1B). Whilst two transcripts are clearly produced (Fig. 1C), the absence of an upstream AUG in the 5' UTR of the longer mRNA make it likely that both transcripts give rise to the same translation product. The AcpA protein is a member of the GPR1/FUN34/YaaH membrane protein family (TC-9.B.33) [7]. When the deduced amino acid sequence of AcpA is subject to analysis using algorithms designed to address membrane protein topology it is predicted to have six unambiguous transmembrane domains flanked by two additional putative domains. The six family-characteristic membrane spanning segments are indicated in Fig. 1A. The two putative membrane spanning segments (not depicted in the Figure) comprise residues 13 to 33 and 268 to 288.

Deletion of acpA affects growth on acetate as sole carbon source at low concentration and in a high pH medium

Using a gene replacement strategy, a complete loss-of-function $\triangle a c p A$ single mutant was constructed as well as a $\triangle a c p A \triangle a l c S$ double deletion mutant (see Experimental). The ability of these mutant strains to grow on different carbon sources was examined by plate testing. While no growth defects were observed on glucose, glycerol or ethanol, the ability of these mutants to utilize acetate appeared to be affected. Acetate is generally used at $0.5 \%$ (w/v of the sodium salt) and Aspergillus media are normally set at $\mathrm{pH} 6.8$, well above the $\mathrm{pKa}$ of acetic acid $\left(4.75\right.$ at $\left.25^{\circ} \mathrm{C}\right)$. [pKa is the $\mathrm{pH}$ value at which the dynamic $\mathrm{pH}$-dependent equilibrium between the protonated (HA) and dissociated $\left(\mathrm{A}^{-}\right)$forms of acetate are present in equimolar concentration. At $\mathrm{pH}$ values below the $\mathrm{pKa}$ this equilibrium is shifted towards the protonated uncharged form whereas higher $\mathrm{pH}$ values result in predominance of the anion]. Plate growth was therefore tested not only at different acetate concentrations but also at different medium $\mathrm{pH}$. As can be seen in Fig. 2, the $\triangle a c p A$ mutants clearly manifest a growth defect at the low acetate concentration $(0.1 \%)$ which is more pronounced at high $\mathrm{pH}$ where the acid becomes increasingly limiting compared to the acetate anion. As could be expected, 
re-introduction of the acpA gene into these gene-deleted mutants fully restored wild-type growth characteristics (data not shown).

Interestingly, growth on acetate was further reduced in the double $\triangle$ acp $A \triangle$ alcS mutant compared to $\triangle a c p A$, whereas a $\triangle a l c S$ mutant grew just as well as the wild-type strain (Fig. 2). A. nidulans is able to utilize agar as a very poor carbon source in the absence of any other growth substrate (i.e. under conditions of carbon starvation), leading to colonies of low hyphal density and sparse sporulation [3]. In this regard, starvation growth of a $\triangle a l c S$ mutant on minimal medium agar plates lacking an added carbon source is compromised compared to that of a wild-type strain or a single $\triangle a c p A$ null mutant (data not shown). This defect in the $\Delta a l c S$ mutant could therefore explain the more severe phenotype observed for the double $\triangle a c p A \Delta a l c S$ mutant on limiting acetate plates.

acpA is required for induction of the acetate-utilization pathway genes by limiting amounts of externally applied acetate

Considering the results presented above, we carried out northern blot experiments to test the ability of acetate to induce the expression of the genes required for acetate utilization, such as $a c u E$, in the $\triangle a c p A$ mutant when acetate is used at $0.1 \%$ (i.e. $7.2 \mathrm{mM}$ ) in medium of pH 6.8 (Fig. 3A). At this pH the dissociated form (A') represents more than $99 \%$ of the acetate molecules. While $a c u E$ is strongly induced under these conditions in a wild-type strain, no induction was observed in the null $\triangle a c p A$ mutant. Deletion of acpA thus results in a phenotypic effect similar to that originally described by Kujau et al. [8] for glyoxylate pathway regulator ( $g p r)$ mutations in Y. lipolytica, including among others gprl mutations. To confirm that the lack of $a c u E$ induction is due to the inability of acetate to enter the cell in this mutant, we also tested the ability of ethanol and ethylacetate (at the same low concentration) to induce $a c u E$ expression in the $\triangle a c p A$ strain. Induction of the acetate-utilization pathway genes by ethanol and ethylacetate is due to the production of acetate resulting from the intracellular catabolism of these carbon sources [24, 27] and hence does not involve any acetate uptake. No differences in the ethanol and ethylacetate induction patterns were observed between the wild-type and the $\triangle a c p A$ mutant strains (Fig. 3B). Conversely, ethanol induction of acuE is absent in alcR mutants (data not shown) as these cannot catabolize ethanol into acetate [1]. These data support the hypothesis that AcpA is involved in the uptake of the dissociated form of acetate.

\section{Expression of the acpA gene is induced by low concentrations of acetate}


In a previous study we reported that $\operatorname{acp} A(A N 5226)$ itself is not induced by acetate but rather expressed at a basal level similar to that observed on lactose [7]. However, in those experiments acetate was used at a concentration of $36 \mathrm{mM}(0.5 \%)$ in non-pH stabilised medium. The present results (described above) indicate that acpA is required primarily when the protonated form of acetate (HA) is present at limiting concentrations that are insufficient for growth. We therefore analysed transcriptional expression of acpA in a wild-type strain grown at pH 6.8 in response to increasing concentrations of acetate (from $7.2 \mathrm{mM}$ to $36 \mathrm{mM}$, i.e. from 0.1 to $0.5 \%$ ) using $a c u E$ as a control. As shown in Fig. 4 acp A is clearly induced by low amounts of acetate, its level of expression apparently being inversely correlated to the acetate concentration; up to $28 \mathrm{mM}, a c u E$ induction appears to follow the opposite trend. This acp $A$ transcription profile can account for the growth phenotypes shown in Fig. 2.

The dramatic drop in the $a c u E$ transcript level observed between 28 and $36 \mathrm{mM}$ of acetate in medium phosphate-buffered at $\mathrm{pH} 6.8$, is most probably a consequence of acetate toxicity. Previously we have noticed that a similar drop in the $\gamma$-actin (acnA) transcript level occurs between 36 and $40 \mathrm{mM}$ in medium set at pH 6.8 (but not phosphate buffered) and that this effect occurs at increasingly lower acetate concentrations with decreasing medium $\mathrm{pH}$ (data not shown).

\section{Transcription pattern of acpA upon addition of various weak carboxylic acids}

To further specify the induction spectrum of $a c p A$ we performed northern blot analysis on RNA isolated from wild-type mycelia supplied with $7.2 \mathrm{mM}$ (final concentration) of various weak monocarboxylic acids: lactate, pyruvate, propionate, formate and glyoxylate. Of these, only addition of propionate results in significant induction of acpA (Fig. 5). Interestingly, this induction is much weaker when propionate is supplied at $36 \mathrm{mM}$ (data not shown), suggesting that the inducing ability of this weak acid is similar to that of acetate (i.e. it provokes transcriptional induction of acp $A$ when present in limiting amounts). While growth was extremely poor on these monocarboxylic acids as sole carbon sources, no significant differences in growth were observed between the $\triangle a c p A$ null mutants and the wild-type (data not shown). Moreover, testing propionate toxicity using a wide range of propionate concentrations on glycerol minimal medium plates (at $\mathrm{pH}$ 6.8) did not discriminate $a c p A$-deleted strains from wild-types (data not shown). These data suggest that AcpA has a restricted substrate range and that acetate is its physiologically relevant substrate.

\section{Transcriptional activation of acpA}


Intriguingly, while the $a c p A$ response to glyoxylate was rather weak at low concentrations (Fig. 5) this intermediate of acetate catabolism provoked a powerful induction at $50 \mathrm{mM}$ (data not shown) - the reverse of that observed for acetate and propionate. It has previously been shown that glyoxylate at $50 \mathrm{mM}$ is also good inducer of the transcription of the acetyl-CoA synthethase gene $f a c A$, one of the structural genes under the control of the acetate pathway-specific activator FacB [27]. These observations prompted us to investigate whether the induction of $a c p A$ is dependent on the function of FacB. To address this we compared the expression of $a c p A$ between a wild-type strain and a $f a c B$ mutant ( $f a c B 101$ ) after induction with ethanol and ethylacetate and used $a c u E$ as an expression control. The lack of acpA induction (Fig. 6) in the complete loss-of-function mutant facB101 [28] correlates with the presence of six putative binding sites for the binuclear zinc-cluster protein FacB [29] in the promoter of the acpA gene: two sites located upstream of the distal transcriptional start and four more located upstream of the proximal start site (Fig. $1 A$ ). The induction pattern of acp $A$ in a $f a c A$ mutant $(f a c A 330)$ - the latter cannot convert acetate into acetyl-CoA - is similar to that observed in the wild-type strain, indicating that the loss of induction in the facB 101 mutant is due to the absence of functional FacB and not a consequence of the loss of the ability to catabolize acetate. It should be noted that our analysis suggests that the basal level (i.e. non-induced) expression of both $a c p A$ transcripts does not require FacB.

\section{acpA is essential for acetate permease activity}

To assess the role of $a c p A$ in acetate transport the uptake of ${ }^{14} \mathrm{C}$-labelled acetate was compared between wild-type and $\triangle a c p A$ null mutant conidia germinating in the presence of either glucose or ethanol as sole carbon sources, culture conditions known to result in acp $A$ expression (data not shown). As can be seen in Fig. 7 acetate uptake by $\triangle a c p A$ conidia is very considerably reduced compared to that of wild-type conidia. This is especially true at the lower acetate concentrations where the differences in calculated uptake rates range from 30 fold at $1 \mathrm{mM}$ acetate to $>100$ fold at acetate concentrations between $1-100 \mu \mathrm{M}$. To characterise the kinetics of acetate uptake the incorporation of ${ }^{14} \mathrm{C}$-acetate by wild-type conidia germinating in glucose at $\mathrm{pH} 6.8$ was measured across a wide range of substrate concentrations ( $1 \mu \mathrm{M}-7 \mathrm{mM}$ ). Rates of uptake were obtained by linear regression of plots of acetate incorporation versus time. Rates plotted against substrate concentration showed Michaelis-Menten saturation kinetics from which a Km of $\sim 230 \mu \mathrm{M}$ was calculated (Fig. 7 inset). Eadie-Hofstee and Hanes-Wolf representations of the data were monophasic hence indicating that no additional system of acetate incorporation contributed significantly to its 
uptake. These data are consistent with the growth phenotype of the $\triangle a c p A$ mutants on limiting amounts of acetate being due to an impairment of the uptake of the acetate anion, and the likelihood that AcpA functions as an acetate permease in $A$. nidulans.

\section{DISCUSSION}

In this paper we identify acpA (Broad annotation: AN5226) to encode a novel element in the biochemical pathway for acetate utilization in the filamentous fungus Aspergillus nidulans. The acpA gene is located on chromosome $\mathrm{V}$ but it is not closely physically linked to any of the five other loci involved in acetate metabolism that also reside on this chromosome: facA (AN5626), acuD (AN5634), acuG (AN5604), acuH (AN5336) and acuN (AN5746) [3]. Analysis of the sequence of the deduced translation product (AcpA) is indicative of a membrane related function since it bears homology to the defining members of the GPR1/FUN34/YaaH family (TC-9.B.33; Pfam PF01184) of membrane proteins [12, 30, 31], and its hydrophobicity profile indicates the presence of six transmembrane domains.

Unlike other activities involved in acetate utilization, AcpA is dispensable for growth on the acetate precursor ethanol. Whilst this is also largely the case when $1 \%$ acetate is used as the sole carbon source, at reduced concentrations the growth of AcpA loss-of-function mutants $(\triangle a c p A)$ is seen to become progressively impaired and this effect is further exacerbated at elevated $\mathrm{pH}$. Previous studies of acetate uptake kinetics in yeast have provided evidence for distinct means of uptake for each of the two forms of acetate (i.e. HA and $\mathrm{A}^{-}$). Entry of the anion into the cell is mediated by a transport system whilst the undissociated acid is able to freely diffuse across the plasma membrane $[32,33]$. The very poor growth observed for $A$. nidulans $\triangle a c p A$ mutants on acetate under conditions in which the availability of the protonated (HA) form is very reduced or negligible (i.e. low acetate concentration and $\mathrm{pH}$ values considerably higher than the $\mathrm{pKa}$ ) could thus be indicative of a defect in the transport of the anionic form. This is coherent with the observation of normal growth of $\triangle a c p A$ mutants on ethanol since acetate is generated intracellularly upon catabolism of ethanol.

In addition to the growth phenotype on acetate, deletion of acp $A$ results in altered regulation of the malate synthase $(a c u E)$ gene. Whilst $a c u E$ inducibility upon growth of $\triangle a c p A$ mutants on acetate precursor substrates is unchanged from that of wild-type, its induction by limiting amounts of externally supplied acetate $(0.1 \%$ at medium $\mathrm{pH} 6.8)$ is absent. Furthermore, the acp $A$ transcript level in wild-type strains increases as the external acetate concentration decreases, i.e. the gene's response coincides with the need for a means to take up the acetate anion. These results are all consistent with the loss of an acetate uptake 
function in the acpA deletion mutant. Indeed, direct measurement of acetate incorporation into germinating conidia confirmed the effect of the acp $A$ deletion on acetate uptake. At low substrate (acetate) concentrations acetate uptake is almost completely lost in acpA-deleted conidia compared to that seen in wild-type.

It has previously been postulated [34] that a gene (GenBank accession AY236409) corresponding to the A. nidulans Broad locus AN2840 could encode a monocarboxylate transporter (MCT) based on its similarity to functional mammalian MCTs. However, in $S$. cerevisiae of the five proteins that show substantial similarity to human MCT transporters none is important for the transport of carboxylic acids across the plasma membrane, and most are instead found associated with intracellular structures [35]. To our knowledge, AcpA is thus the first experimentally supported candidate for a MCT in filamentous fungi.

By reciprocal TBLASTN screening we searched for AcpA orthologues in publicly available fungal genome databases. In all cases except that of the Chytridiomycota at least one putative orthologue of acpA could be identified. Fig. 8 shows a phylogenetic tree of those proteins most similar to AcpA in 27 fungi. The proteins identified in the Aspergilli share 61\% identity and $74 \%$ similarity. These data indicate conservation of AcpA-like proteins and by inference the means of direct cellular uptake of the acetate ion.

With regard to their structural organisation, all Aspergillus spp acpA orthologues appear to contain canonical splicing sites [36] in their 5' UTR sequences that encompass a region highly enriched in A residues (for $A$. nidulans see Fig. 1A nucleotide position -72 to 35). The apparent occurrence of an intron upstream of the coding region in all Aspergilli acpA orthologues suggests not only structural conservation within the 5' UTR sequences but also a specific function for the intron. A similar organization is known for the A. nidulans gene brlA which encodes a key regulator of asexual development. The molecular basis for the production of two distinct $b r l A$ transcripts and translation products has been studied [37, 38]. In the case of acpA however, the absence of any ATG in the 5' UTR of the longer transcript would suggest that both mRNA species probably give rise to the same translation product. This raises the question of the roles of the two acpA transcripts. One possibility can be illustrated by the S. cerevisiae JEN1 gene [39]. For this gene, one of the several different transcription products that result from multiple initiation transcription sites was shown to modulate the degradation of all JEN1-specific mRNAs [40]. Another gene with an intron in its 5'UTR is the arginase encoding gene agaA of $A$. nidulans [41]. This intron leads to the generation of various mRNA isoforms that influence not only mRNA stability but also their 
activities as templates for translation by a riboswitch mechanism [42]. However, unlike acpA, the different agaA mRNA species result from alternative splicing.

In $S$. cerevisiae two functional MCTs have been described: a high-affinity transporter shared by lactate, acetate, propionate and pyruvate [43], and a second transporter of lower affinity and more restricted substrate specificity since it only transports acetate, propionate and formate [32]. While the former was found to be Jen1p (TC-2.A.1.12.2) [39, 44] a membrane protein that is assigned to the Major Facilitator Superfamily (TC-2.A.1), the latter depends on the integrity of the yeast acp $A$ orthologue, $A D Y 2$ [11].

By screening the A. nidulans genome sequence [14] we identified two putative gene products similar to $S$. cerevisiae Jen1p encoded by loci AN6703 and AN6095. The deduced proteins share $39 \%$ and $30 \%$ identity with Jen 1 p, respectively. Northern blot analysis upon addition of various monocarboxylic acids or ethanol to lactose-grown wild-type mycelia, failed to reveal expression of AN6095 (unpublished data). By contrast, AN6703 appeared to be modestly expressed upon formate and propionate induction but no response could be observed upon addition of acetate to $7.2 \mathrm{mM}$ or $36 \mathrm{mM}(0.1 \%-0.5 \%)$ nor in the presence of ethanol (i.e. under conditions inducing for the acpA gene) (unpublished data). These observations would explain why conidia of the null $\triangle a c p A$ mutant germinated on glucose or ethanol are barely able to take up acetate under our experimental conditions (medium $\mathrm{pH}$ of 6.8 or higher - see Fig. 7). Alternative explanations could be that AN6703, the A. nidulans protein most similar to the yeast transporter Jen $1 p$, is either unable to transport acetate or as is the case for ethanol - it is not expressed on glucose.

Together with previous yeast studies [11-13], our data demonstrate a link between members of the GPR1/FUN34/YaaH protein family (TC-9.B.33) and acetate utilisation, suggesting that other members of this family, including A. nidulans AlcS and orthologues in other filamentous fungi, might be involved in acetate adaptation, uptake and/or catabolism.

\section{ACKNOWLEDGEMENTS}

This work was supported by the Centre National de la Recherche Scientifique (CNRS: contrat ATIP 2JE077). X.R. was a recipient of doctoral fellowship from the Ministère de l'Enseignement Supérieur et de la Recherche of the French Government and is currently supported by The Human Earth Foundation. M.F. is the recipient of a postdoctoral contract Ramón y Cajal from the Spanish Ministerio de Educación y Ciencia. We thank Drs Nathalie Oestreicher, Béatrice Felenbok and Claudio Scazzocchio for fruitful discussions, and Dr. Barry Holland for correcting the English. 


\section{REFERENCES}

1 Felenbok, B., Flipphi, M. and Nikolaev, I. (2001) Ethanol catabolism in Aspergillus nidulans: a model system for studying gene regulation, Prog. Nucleic Acid Res. Mol. Biol. 69, 149-204

2 Sandeman, R. A. and Hynes, M. J. (1989) Isolation of the facA (acetyl-coenzyme A synthetase) and $a c u E$ (malate synthase) genes of Aspergillus nidulans, Mol. Gen. Genet. 218, 87-92

3 Armitt, S., McCullough, W. and Roberts, C. F. (1976) Analysis of acetate nonutilizing ( $a c u$ ) mutants in Aspergillus nidulans, J. Gen. Microbiol. 92, 263-282

4 Ballance, D. J. and Turner, G. (1986) Gene cloning in Aspergillus nidulans: isolation of the isocitrate lyase gene ( $a c u D)$, Mol. Gen. Genet. 202, 271-275

5 Todd, R. B., Murphy, R. L., Martin, H. M., Sharp, J. A., Davis, M. A., Katz, M. E. and Hynes, M. J. (1997) The acetate regulatory gene facB of Aspergillus nidulans encodes a Zn(II)2Cys6 transcriptional activator, Mol. Gen. Genet. 254, 495-504

6 Fillinger, S. and Felenbok, B. (1996) A newly identified gene cluster in Aspergillus nidulans comprises five novel genes localized in the alc region that are controlled both by the specific transactivator AlcR and the general carbon-catabolite repressor CreA, Mol. Microbiol. 20, 475-488

7 Flipphi, M., Robellet, X., Dequier, E., Leschelle, X., Felenbok, B. and Vélot, C. (2006) Functional analysis of alcS, a gene of the alc cluster in Aspergillus nidulans, Fungal Genet. Biol 43, 247-260

8 Kujau, M., Weber, H. and Barth, G. (1992) Characterization of mutants of the yeast Yarrowia lipolytica defective in acetyl-coenzyme A synthetase, Yeast 8, 193-203

9 Rabitsch, K. P., Tóth, A., Gálová, M., Schleiffer, A., Schaffner, G., Aigner, E., Rupp, C., Penkner, A. M., Moreno-Borchart, A. C., Primig, M., Esposito, R. E., Klein, F., Knop, M. and Nasmyth, K. (2001) A screen for genes required for meiosis and spore formation based on whole-genome expression, Curr. Biol. 11, 1001-1009

10 Stettler, S., Mariotte, S., Riva, M., Sentenac, A. and Thuriaux, P. (1992) An essential and specific subunit of RNA polymerase III (C) is encoded by gene RPC34 in Saccharomyces cerevisiae, J. Biol. Chem. 267, 21390-21395

11 Paiva, S., Devaux, F., Barbosa, S., Jacq, C. and Casal, M. (2004) Ady2p is essential for the acetate permease activity in the yeast Saccharomyces cerevisiae, Yeast $\mathbf{2 1}$, 201-210 
12 Augstein, A., Barth, K., Gentsch, M., Kohlwein, S. D. and Barth, G. (2003) Characterization, localization and functional analysis of Gpr1p, a protein affecting sensitivity to acetic acid in the yeast Yarrowia lipolytica, Microbiology 149, 589-600

13 Gentsch, M., Kuschel, M., Schlegel, S. and Barth, G. (2007) Mutations at different sites in members of the Gpr1/Fun34/YaaH protein family cause hypersensitivity to acetic acid in Saccharomyces cerevisiae as well as in Yarrowia lipolytica, FEMS Yeast Res. 7, 380-390

14 Galagan, J. E., Calvo, S. E., Cuomo, C., Ma, L. J., Wortman, J. R., Batzoglou, S., Lee, S. I., Bastürkmen, M., Spevak, C. C., Clutterbuck, J., Kapitonov, V., Jurka, J., Scazzocchio, C., Farman, M., Butler, J., Purcell, S., Harris, S., Braus, G. H., Draht, O., Busch, S., D'Enfert, C., Bouchier, C., Goldman, G. H., Bell-Pedersen, D., GriffithsJones, S., Doonan, J. H., Yu, J., Vienken, K., Pain, A., Freitag, M., Selker, E. U., Archer, D. B., Peñalva, M. A., Oakley, B. R., Momany, M., Tanaka, T., Kumagai, T., Asai, K., Machida, M., Nierman, W. C., Denning, D. W., Caddick, M., Hynes, M., Paoletti, M., Fischer, R., Miller, B., Dyer, P., Sachs, M. S., Osmani, S. A. and Birren, B. W. (2005) Sequencing of Aspergillus nidulans and comparative analysis with $A$. fumigatus and A. oryzae, Nature 438, 1105-1115

15 Clutterbuck, A. J. (1993) in Genetic Maps: Locus Maps of Complex Genomes, vol. 3 (O'Brien, S. J., ed.), pp. 71-84, Cold Spring Harbor Laboratory Press, Cold Spring Harbor

16 Cove, D. J. (1966) The induction and repression of nitrate reductase in the fungus Aspergillus nidulans, Biochim. Biophys. Acta 113, 51-56

17 Sambrook, J. and Russel, D. W. (2001) Molecular Cloning : A laboratory Manual, Cold Spring Harbor Laboratory Press, NY

18 Specht, C. A., DiRusso, C. C., Novotny, C. P. and Ullrich, R. C. (1982) A method for extracting high-molecular-weight deoxyribonucleic acid from fungi, Anal. Biochem. 119, $158-163$

19 Clutterbuck, A. J. (1974) in Handbook of genetics. Bacteria, Bacteriophages, and Fungi, vol. 1 (King, R. C., ed.), pp. 447-510, Plenum Press, New York, London

20 Tilburn, J., Scazzocchio, C., Taylor, G. G., Zabicky-Zissman, J. H., Lockington, R. A. and Davies, R. W. (1983) Transformation by integration in Aspergillus nidulans, Gene 26, 205-221 
21 Yu, J. H., Hamari, Z., Han, K. H., Seo, J. A., Reyes-Domínguez, Y. and Scazzocchio, C. (2004) Double-joint PCR: a PCR-based molecular tool for gene manipulations in filamentous fungi, Fungal Genet. Biol. 41, 973-981

22 Kurtov, D., Kinghorn, J. R. and Unkles, S. E. (1999) The Aspergillus nidulans panB gene encodes ketopantoate hydroxymethyltransferase, required for biosynthesis of pantothenate and Coenzyme A, Mol. Gen. Genet. 262, 115-120

23 Forment, J. V., Flipphi, M., Ramón, D., Ventura, L. and MacCabe, A. P. (2006) Identification of the $m s t E$ gene encoding a glucose-inducible, low affinity glucose transporter in Aspergillus nidulans, J. Biol. Chem. 281, 8339-8346

24 Flipphi, M., Kocialkowska, J. and Felenbok, B. (2003) Relationships between the ethanol utilization (alc) pathway and unrelated catabolic pathways in Aspergillus nidulans, Eur. J. Biochem. 270, 3555-3564

25 Flipphi, M., van de Vondervoort, P. J. I., Ruijter, G. J. G., Visser, J., Arst, H. N., Jr. and Felenbok, B. (2003) Onset of carbon catabolite repression in Aspergillus nidulans. Parallel involvement of hexokinase and glucokinase in sugar signaling, J. Biol. Chem. 278, 11849-11857

26 MacCabe, A. P., Miró, P., Ventura, L. and Ramón, D. (2003) Glucose uptake in germinating Aspergillus nidulans conidia: involvement of the creA and sor A genes, Microbiology 149, 2129-2136

27 Flipphi, M., Kocialkowska, J. and Felenbok, B. (2002) Characteristics of physiological inducers of the ethanol utilization (alc) pathway in Aspergillus nidulans, Biochem. J. 364, 25-31

28 Todd, R. B., Kelly, J. M., Davis, M. A. and Hynes, M. J. (1997) Molecular characterization of mutants of the acetate regulatory gene facB of Aspergillus nidulans, Fungal Genet. Biol. 22, 92-102

29 Todd, R. B., Andrianopoulos, A., Davis, M. A. and Hynes, M. J. (1998) FacB, the Aspergillus nidulans activator of acetate utilization genes, binds dissimilar DNA sequences, EMBO J. 17, 2042-2054

30 Kim, H., Melén, K. and von Heijne, G. (2003) Topology models for 37 Saccharomyces cerevisiae membrane proteins based on C-terminal reporter fusions and predictions, J. Biol. Chem. 278, 10208-10213

31 Daley, D. O., Rapp, M., Granseth, E., Melén, K., Drew, D. and von Heijne, G. (2005) Global topology analysis of the Escherichia coli inner membrane proteome, Science 308, 1321-1323 
32 Casal, M., Cardoso, H. and Leão, C. (1996) Mechanisms regulating the transport of acetic acid in Saccharomyces cerevisiae, Microbiology 142, 1385-1390

33 Casal, M. and Leão, C. (1995) Utilization of short-chain monocarboxylic acids by the yeast Torulaspora delbrueckii: specificity of the transport systems and their regulation, Biochim. Biophys. Acta 1267, 122-130

34 Semighini, C. P., Goldman, M. H. and Goldman, G. H. (2004) Multi-copy suppression of an Aspergillus nidulans mutant sensitive to camptothecin by a putative monocarboxylate transporter, Curr. Microbiol 49, 229-233

35 Makuc, J., Paiva, S., Schauen, M., Krämer, R., André, B., Casal, M., Leão, C. and Boles, E. (2001) The putative monocarboxylate permeases of the yeast Saccharomyces cerevisiae do not transport monocarboxylic acids across the plasma membrane, Yeast 18, 1131-1143

36 Kupfer, D. M., Drabenstot, S. D., Buchanan, K. L., Lai, H., Zhu, H., Dyer, D. W., Roe, B. A. and Murphy, J. W. (2004) Introns and splicing elements of five diverse fungi, Eukaryot. Cell 3, 1088-1100

37 Prade, R. A. and Timberlake, W. E. (1993) The Aspergillus nidulans brlA regulatory locus consists of overlapping transcription units that are individually required for conidiophore development, EMBO J. 12, 2439-2447

38 Han, S., Navarro, J., Greve, R. A. and Adams, T. H. (1993) Translational repression of brlA expression prevents premature development in Aspergillus, EMBO J. 12, 24492457

39 Casal, M., Paiva, S., Andrade, R. P., Gancedo, C. and Leão, C. (1999) The lactateproton symport of Saccharomyces cerevisiae is encoded by JEN1, J. Bacteriol. 181, $2620-2633$

40 Andrade, R. P., Kötter, P., Entian, K. D. and Casal, M. (2005) Multiple transcripts regulate glucose-triggered mRNA decay of the lactate transporter JEN1 from Saccharomyces cerevisiae, Biochem. Biophys. Res. Commun. 332, 254-262

41 Borsuk, P., Dzikowska, A., Empel, J., Grzelak, A., Grzeskowiak, R. and Weglenski, P. (1999) Structure of the arginase coding gene and its transcript in Aspergillus nidulans, Acta Biochim. Pol. 46, 391-403

42 Borsuk, P., Przykorska, A., Blachnio, K., Koper, M., Pawlowicz, J. M., Pekala, M. and Weglenski, P. (2007) L-Arginine influences the structure and function of arginase mRNA in Aspergillus nidulans, Biol. Chem. 388, 135-144 
43 Cássio, F., Leão, C. and van Uden, N. (1987) Transport of lactate and other shortchain monocarboxylates in the yeast Saccharomyces cerevisiae, Appl. Environ. Microbiol. 53, 509-513

44 Andrade, R. P. and Casal, M. (2001) Expression of the lactate permease gene JEN1 from the yeast Saccharomyces cerevisiae, Fungal Genet. Biol. 32, 105-111

45 Flipphi, M., Mathieu, M., Cirpus, I., Panozzo, C. and Felenbok, B. (2001) Regulation of the aldehyde dehydrogenase gene ( $\operatorname{ald} A)$ and its role in the control of the coinducer level necessary for induction of the ethanol utilization pathway in Aspergillus nidulans, J. Biol. Chem. 276, 6950-6958

46 Apirion, D. (1965) The two-way selection of mutants and revertants in respect of acetate utilization and resistance to fluoro-acetate in Aspergillus nidulans, Genet. Res. 6, 317-329

47 von Heijne, G. (1992) Membrane protein structure prediction. Hydrophobicity analysis and the positive-inside rule, J. Mol. Biol. 225, 487-494

48 Thompson, J. D., Higgins, D. G. and Gibson, T. J. (1994) CLUSTAL W: improving the sensitivity of progressive multiple sequence alignment through sequence weighting, position-specific gap penalties and weight matrix choice, Nucleic Acids Res. 22, 4673-4680

49 Felsenstein, J. (1989) PHYLIP - Phylogeny Inference Package (Version 3.2), Cladistics 5, 164-166 
Table 1. A. nidulans strains used in this study.

\begin{tabular}{|c|c|c|}
\hline Strain & Genotype & $\begin{array}{l}\text { Source or } \\
\text { reference }\end{array}$ \\
\hline BF107 & yA2 pabaA1, aldA67 $7^{1}$ & {$[45]$} \\
\hline CV061 & $w A 3$, pyro $A 4$, fac $A 330^{4,5}$ & \\
\hline CV160 & $y A 2$ pabaAl $1^{1}$ & Henk v \\
\hline CV164 & pabaA1, panB100, riboB $2^{1,2,3}$ & This work \\
\hline CV171 & pyrG89 pabaA1, panB100, riboB2; Tr. $\Delta a l c S$ : & This work \\
\hline CV253 & pyrG89 pabaA1, panB100, riboB2; Tr. $\Delta a l c S: \because A . J$ & This work \\
\hline & $\Delta a c p A:: \operatorname{panB}^{1,2,5}$ & \\
\hline CV260 & pabaA1, panB100, riboB2; Tr. $\triangle a c p A:$ panB $^{1,2,5}$ & This work \\
\hline CV312 & pabaA1, panB100, riboB2; Tr. panB ${ }^{1,2}$ & This work \\
\hline CV313 & pyrG89 pabaA1, panB100, riboB2; Tr. $\Delta a l c S: \because A . f . p y r G, p a n B^{1,2}$ & This work \\
\hline ED027 & $w A 3$, riboB 2 facB $101^{2,5}$ & {$[46]$} \\
\hline
\end{tabular}

1 Para-Amino Benzoic Acid auxotroph; ${ }^{2}$ Riboflavin auxotroph; ${ }^{3}$ D-Pantothenic acid auxotroph; ${ }^{4}$ Pyridoxine auxotroph; ${ }^{5}$ Growth defect on acetate $(0.1 \%)$.

A.f.: Aspergillus fumigatus; Tr: 'transformed with'. 


\section{Table 2. Oligonucleotides used in this study.}

The shift from lower case to upper case corresponds to the junction between sequences from acp $A$ and $p a n B$.

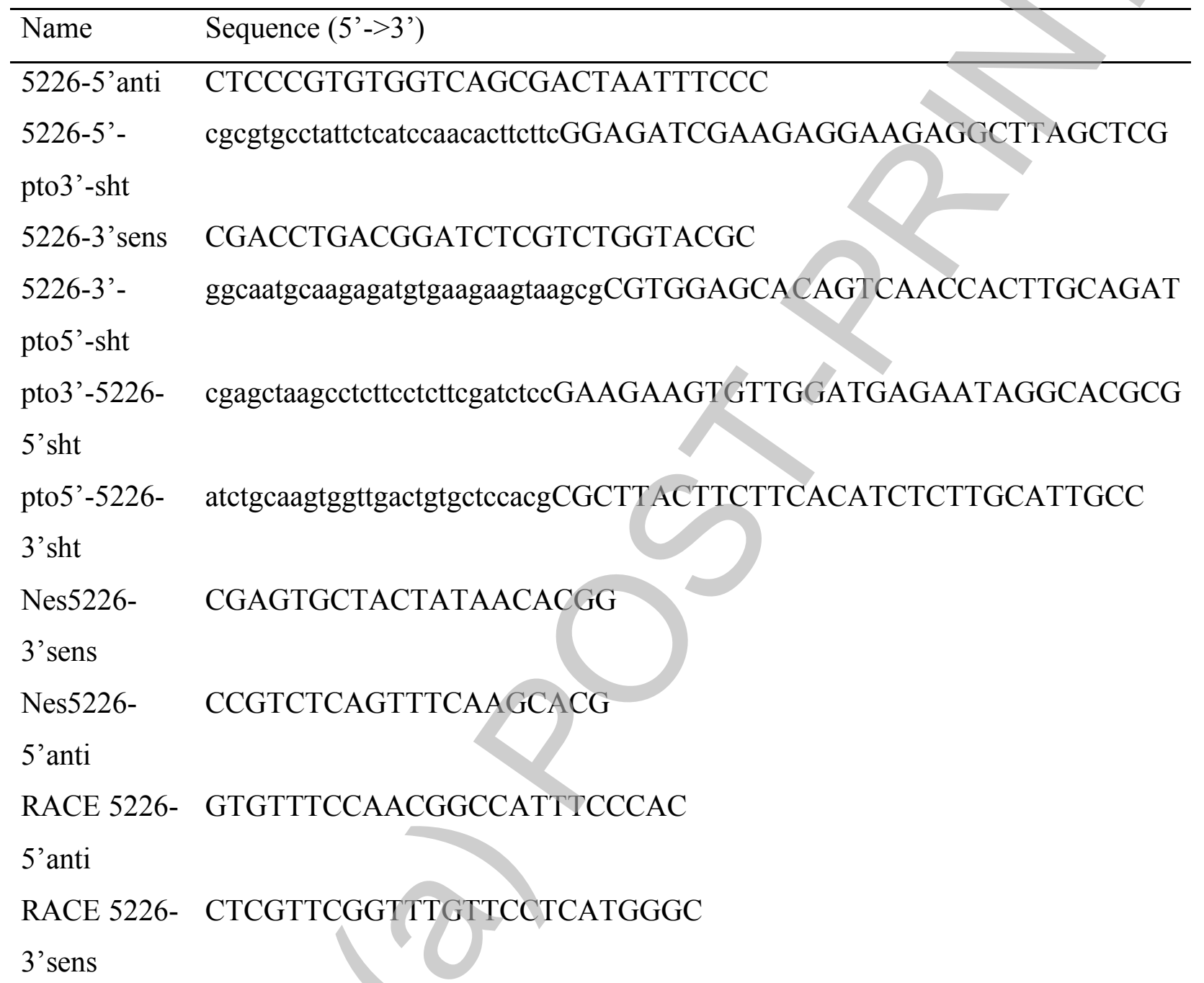




\section{Figure legends}

Figure 1: Structure of the $A$. nidulans acp $A$ gene and its transcription and translation products. (A) The acpA gene corresponds to the predicted ORF AN5226.3 on chromosome $\mathrm{V}$ in the $A$. nidulans genome. The sequence of $a c p A$ is available under GenBank accession number EF428327. All distances are relative to the first base of the presumed start codon for the AcpA protein $(+1)$. The putative FacB-binding sites (class A consensus: $\mathrm{TCC} / \mathrm{GN}_{8}$ ${ }_{10} \mathrm{C} / \mathrm{GGA}$; class B consensus: GCA/CN $\mathrm{CN}_{810} \mathrm{~T} / \mathrm{GGC}$ ) [29] are indicated by dotted box and solid boxes, respectively. The two transcription starts and the major polyadenylation site are indicated by a grey background and labelled '5' L', '5'S' and '3', respectively. The intron within the 5' UTR is indicated by a grey background. Inside this intron, the ATG and Stop codons that bound an ORF are underlined. The two introns disrupting the coding region are marked A and B. The deduced 298 residue sequence of the AcpA protein is given below the coding sequences. The six 21 amino acid long transmembrane domains predicted by the TopPred algorithm [47] (parameter settings: full window size 21, core window size 13, wedge window size 4) are indicated by the grey background. (B) Schematic representation of the two transcripts of $a c p A$. The thick line represents genomic DNA while thin lines represent the two mRNA species. DNA coordinates are relative to the first base of the presumed start codon of the AcpA protein $(+1)$. The positions of the two transcription start sites are marked '5'L' and '5'S'. Probes A and B were used for northern experiments. (C) Northern experiments were realized with RNA isolated from a $\Delta a l c S$ strain (CV171) induced with $50 \mathrm{mM}$ ethylacetate (see Experimental). The blots were subsequently hybridised with the appropriate ${ }^{32}$ P-labelled probes (see Fig. $1 B$ ).

Figure 2: The $\operatorname{acp} A$ gene is required for growth on acetate minimal medium plates. Plates with appropriately supplemented minimal medium were prepared containing sodium nitrate $(10 \mathrm{mM})$ as nitrogen source and sodium acetate at the indicated concentration as the carbon source. The media were buffered at the indicated $\mathrm{pH}$ with $100 \mathrm{mM}$ sodium phosphate (final concentration). Inoculated plates were incubated at $37^{\circ} \mathrm{C}$ for 2 days. The relative availabilities of the protonated (HA) and anionic $\left(\mathrm{A}^{-}\right)$forms are given by the $[\mathrm{HA}]:\left[\mathrm{A}^{-}\right]$ratio for each $\mathrm{pH}$. (A) Plates were point inoculated with four strains which differ only in the indicated deletion: the single mutants $\triangle a c p A$ (strain CV260) and $\triangle a l c S$ (strain CV313), and the double mutant $\triangle a c p A \Delta a l c S$ (strain CV253); strain CV312 was used as the control (see Table 1). 
Figure 3: Malate synthase gene (acuE) transcription in the presence of a limiting amount of acetate depends on the integrity of the acp $A$ gene. Fungal biomass was generated in lactose/urea liquid media and gene expression was induced/repressed with the indicated compounds by addition to mycelial cultures to a final concentration of $7.2 \mathrm{mM}$. Media were buffered at pH 6.8 with $100 \mathrm{mM}$ sodium phosphate. Total RNA was isolated, denatured, separated and transferred to a nylon membrane as described in Experimental. Northern blots were subsequently hybridised with ${ }^{32} \mathrm{P}$-labelled probes corresponding to the indicated genes (see Experimental). The $\gamma$-actin gene (acnA) served as an internal control. CV260 provided the $\triangle a c p A$ mutant background and CV312 served as the wild-type strain (see Table 1). (A) For induction, acetate was added to the mycelial cultures to a final concentration of $7.2 \mathrm{mM}(0.1 \%)$. The control, NI, received no inducer compound. (B) The same experiment was carried out except that ethanol or ethylacetate were added for induction instead of acetate.

Figure 4: Induction of $\operatorname{acp} A$ is inversely correlated to the acetate concentration. Experimental details are as described in the legend to Figure 3. Gene expression was induced with acetate across a range of concentrations from $7.2 \mathrm{mM}(0.1 \%)$ to $36 \mathrm{mM}(0.5 \%)$. The wild-type strain used was CV312 (see Table 1).

Figure 5: $\operatorname{acp} A$ expression in the presence of various weak monocarboxylic acids. Experimental details are as described in the legend to Figure 3. The indicated compounds were added to mycelial lactose cultures to a final concentration of $7.2 \mathrm{mM}$. The wild-type strain used was CV312 (see Table 1).

Figure 6: Involvement of the transcriptional activator of acetate catabolism FacB in $\boldsymbol{a c p} \boldsymbol{A}$ induction. Experimental details are as described in the legend to Figure 3 except that the final concentration of ethanol or ethylacetate was $50 \mathrm{mM}$. Strains ED027 and CV061 provided $f a c B$ and $f a c A$ mutant backgrounds, respectively. CV160 was the wild-type strain used.

Figure 7: AcpA is required for acetate uptake at pH 6.8. Acetate uptake by WT (CV312) or $\triangle a c p A \quad(\mathrm{CV} 260)$ conidia germinating in liquid glucose minimal medium (see Experimental) was determined at different concentrations of acetate $(1,10,100,1000$ and 
10,000 $\mu \mathrm{M})$. Inset: Michaelis-Menten plot of acetate uptake rate versus substrate concentration for the wild-type strain. Uptake rates were measured for eighteen different concentrations of acetate. $\mathrm{V}^{\circ}$ is expressed in nmol of acetate taken up per $5 \times 10^{7}$ conidia per second. The solid line represents the best fit for the data. Representative data from one of five independent experiments are shown.

Figure 8: Neighbour-joining phylogenetic analysis of fungal AcpA orthologues. AcpA orthologue proteins were identified by TBLASTN screening of the genome sequence date of the following species: Neosartorya fischeri, Aspergillus fumigatus, Aspergillus clavatus, Aspergillus oryzae, Aspergillus flavus, Aspergillus terreus, Aspergillus niger, Uncinocarpus reesii, Coccidioides immitis, Histoplasma capsulatum, Ascosphaera apis, Botryotinia fuckeliana, Botrytis cinerea, Sclerotinia sclerotiorum, Septoria nodorum, Chaetomium globosum, Podospora anserina, Neurospora crassa, Fusarium verticillioides, Fusarium graminearum, Trichoderma reesei, Saccharomyces cerevisiae, Yarrowia lipolytica, Ustilago maydis, Coprinus cinereus and Rhizopus oryzae. A sequence alignment was generated using the CLUSTALW multiple sequences alignment program [48] and the PHYLIP package [49]. The tree was rooted using protein sequence RO3G_03025 of Rhizopus oryzae as an outgroup. The bootstrap probabilities (calculated using 100 replications) are indicated on each node. For those organisms where a database of deduced proteins was accessible, the corresponding protein annotation code is given (provided that the predicted protein is identical to that we deduced by manual analysis). 


\section{FIGURE 1}

A

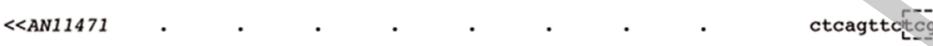

ḡtetcagcaccgajaatgatttgcagttcctttcaccettcgtctctttcctttcccccegctgttttctccgcactctcctttggggttaagaaggetgggcccacggttcagggclacttc

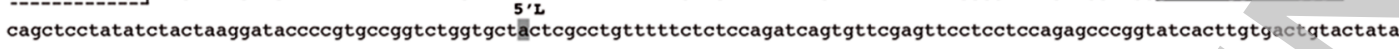
tctcgtcgatcgcagagttcagctaaccgctgctaaaccacccggcgcgactctaagegtctccagtcatcccttttgtggatagcaagctagcaaccggcccatcrcacgcacatcaat

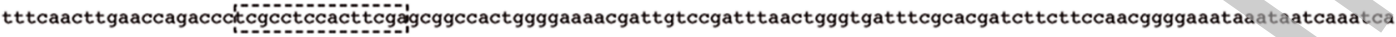
aaccaaaacaaaacggaaggcgagctagttgatcaactaacggtgcttcctccctgtttgggtaagttgctgccaaccctgcgttcgtceggactgctgtccatccagcccatqcatact

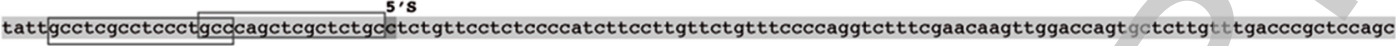
tgtgctgtgcgccacttttttctcttaccttattttttcttcgagctaagcctcttcctcttcgatctccagctagctggtttcgtctaaaacaacaaaaagcaaaaaaaaaaaagc

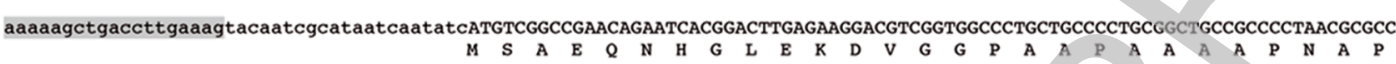

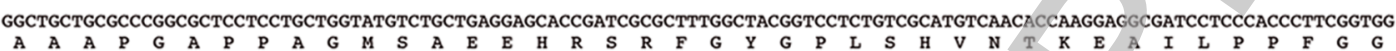
TGAGTTCCAGCCTGGTCTGTACAAGTCGGTCGAGGCGCGCAAGTTTGCCAACCCTGCTCCCCTTGGCCTGAGCGCTTTCGCCCTCACCACTTTCGTGCTGAGCTGTATCAACATGGGTGC

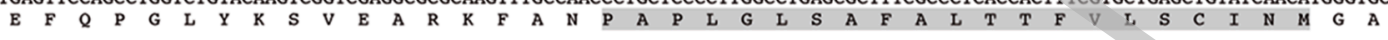
GCGTGACATCACCCACCCTAACATTGTCATTGCTCTGGCCTTCGGTTACGGTGGTCTGGTTCAGTTGCTTGCTGGCATGTGgtaagtgctgCcattgcggtctctgttagtctcgcgggt

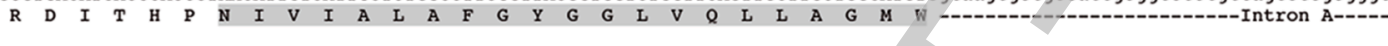
tcagccaggaagctaatcatgagcagGGAAATGGCCGTTGGAAACACTTTTGGTGCCACTGCTCTGTCCTCTTATGGTGGTTTCTGGATTGCGTTCGCCATTGTCCTTACTCCCGGTGGT $\begin{array}{lllllllllllllllllllllllllllll} & \\ \text { TTCAACATTCAGACCGCGCTCACGGCTGAAAATGGTGATGAGGCCATGTTCTACAACTCGTTCGGTTTGTTCCTCATGgtgagtgtttcatcaatacgatcatgaccgttcggcgctgac }\end{array}$

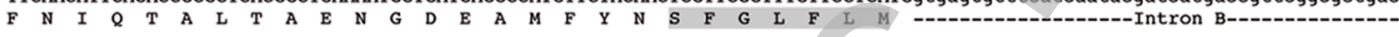
aatgtccccagGGCTGGTTCATCTTCACCACCATCATGCTTTTCTGCACCCTGAGGTCTACCGTCGCCTTCTTCTTGCTGTTCTTGTTCCTCGACCTCGCGTTCCTGCTTCTCGGTGTCG

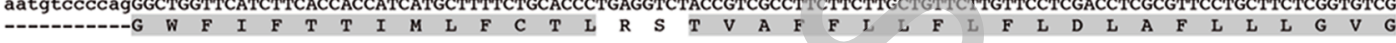

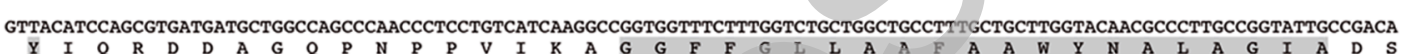

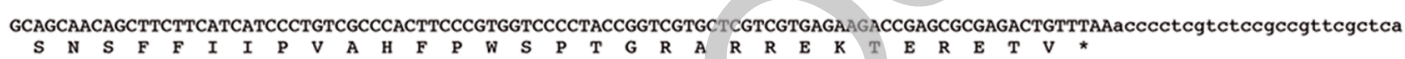
atgaacgaacgggatagcctttgtgetattccggtcgcggtcgtggagcacagtcaaccacttgcagatatagtatagagactgcaataatctcgtcgatacccaacgtaagatcgtcgt tgcgaaagaaccgtgattttggatagaaacaccggtatagggtttcgtcattcttggcagcgatgtatatggtettgcggtatatgaaatcttttctttgtggtttcctatcgatgccct taatatattgattagtcttagttcagtttaatcaaattgtaacgattcaatcc ${ }^{3}$ acctgatccttccaatcctatccttcgagctcttggtcctggatgtgttcctagacaggatagtaa gctcaggtgcgtcatgtcag AN5225>>.

B
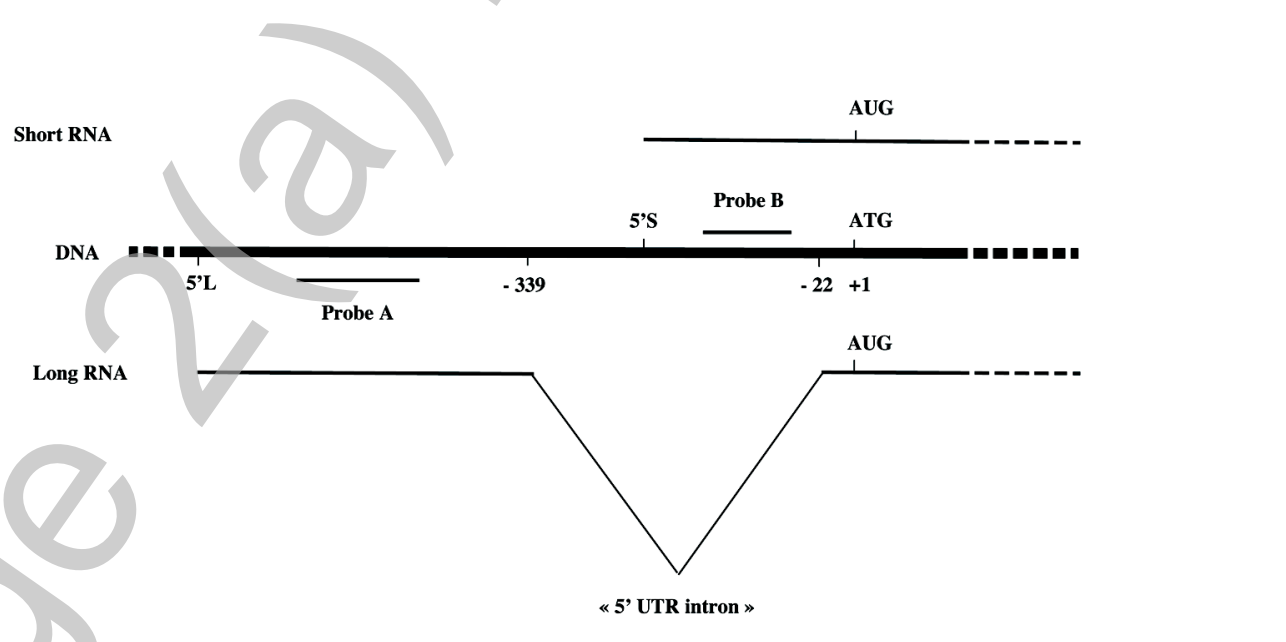

C

acpA

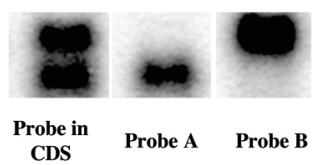

Licenced copy. Copying is not permitted, except with prior permission and as allowed by law. 


\section{FIGURE 2}

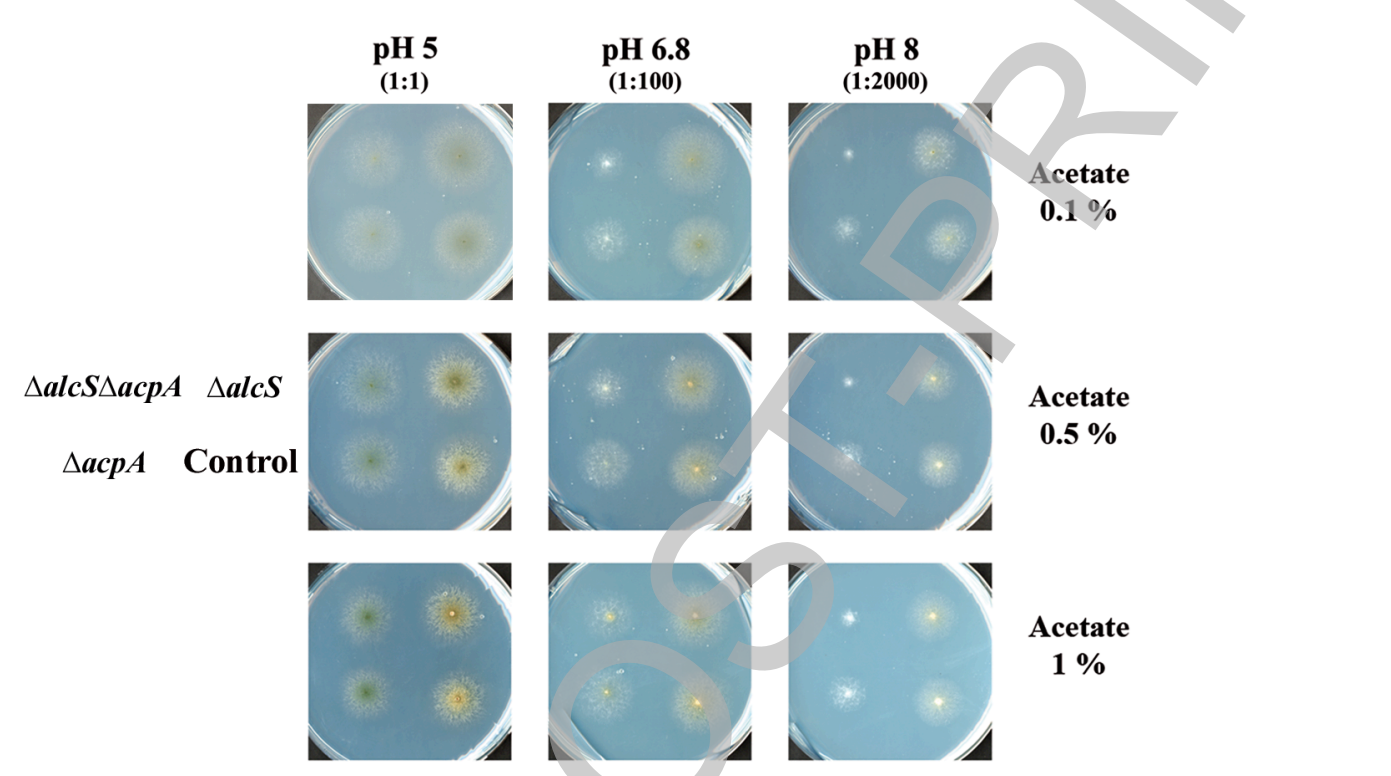




\section{FIGURE 3}

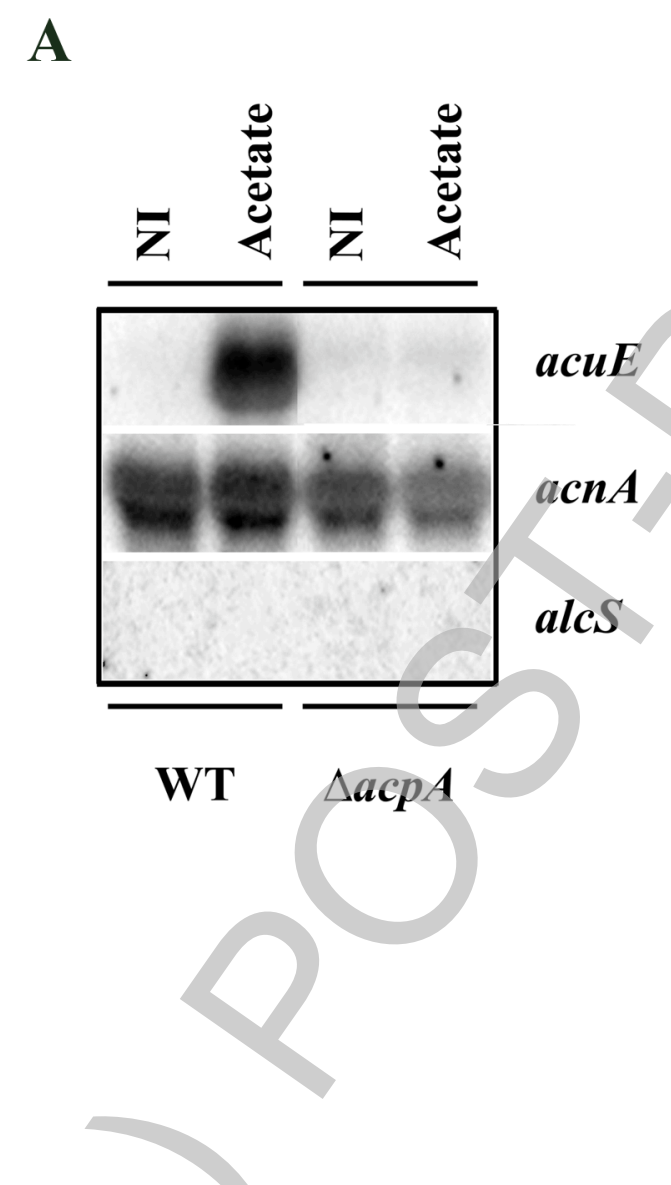

B
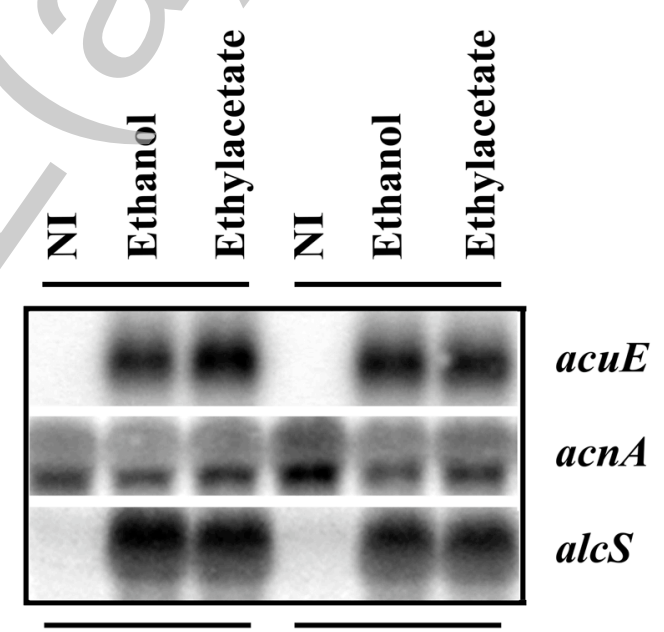

WT

$\triangle \operatorname{acp} A$ 


\section{FIGURE 4}

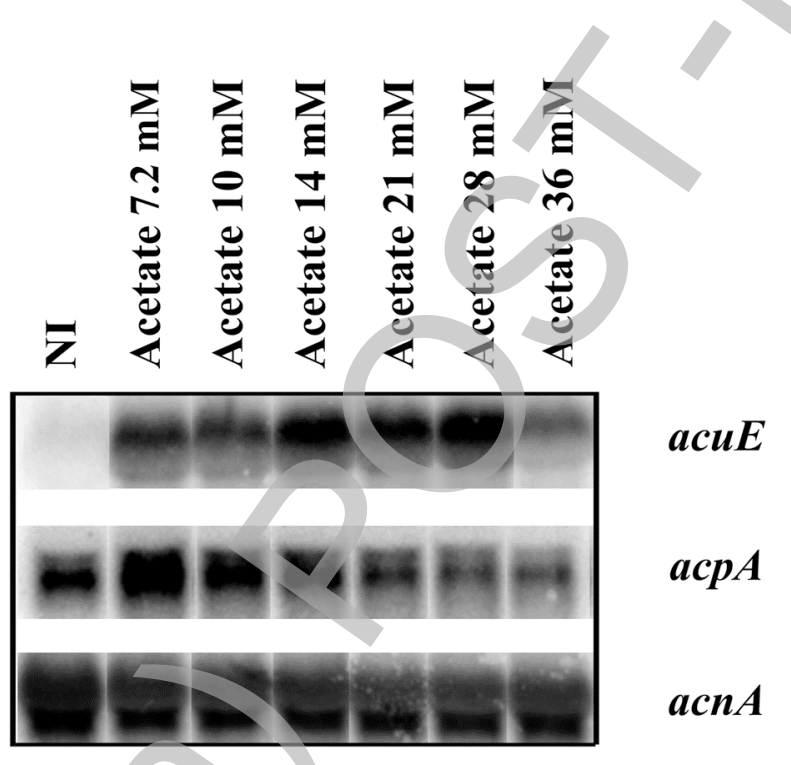

WT 


\section{FIGURE 5}

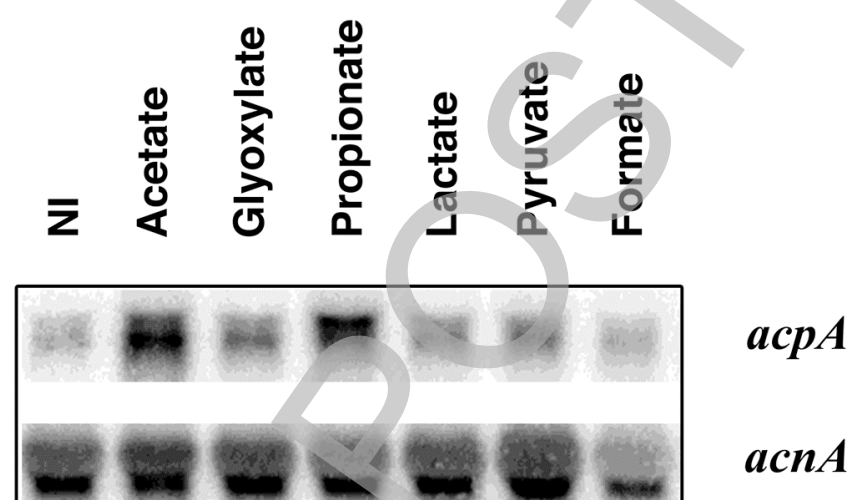




\section{FIGURE 6}

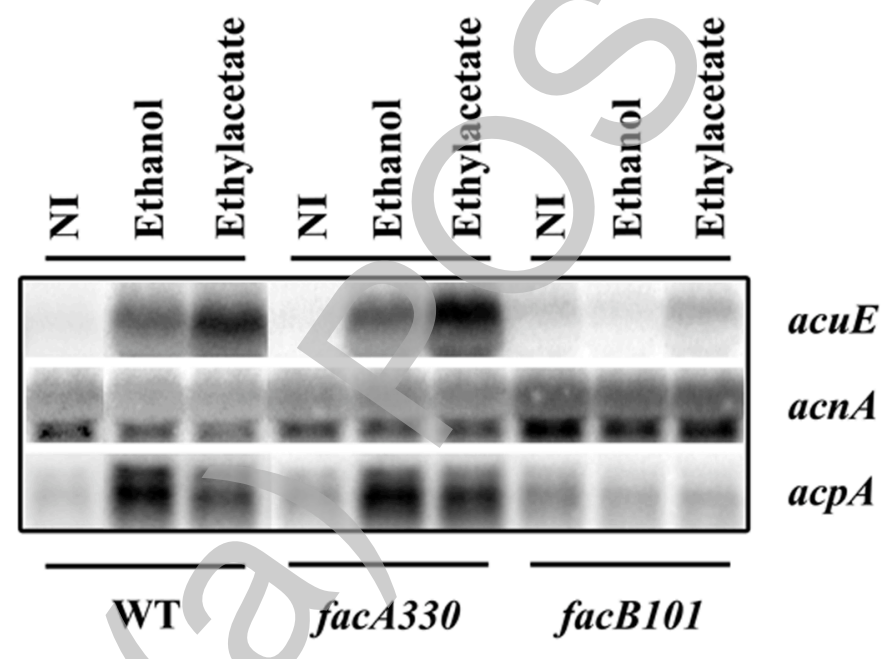




\section{FIGURE 7}

WT

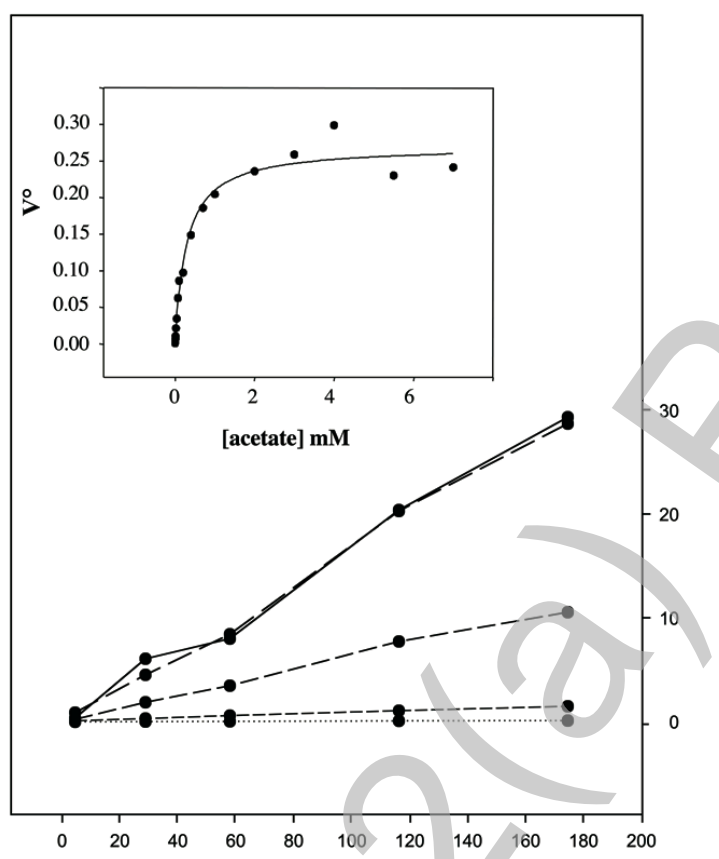

Time (seconds) $\triangle a c p A$

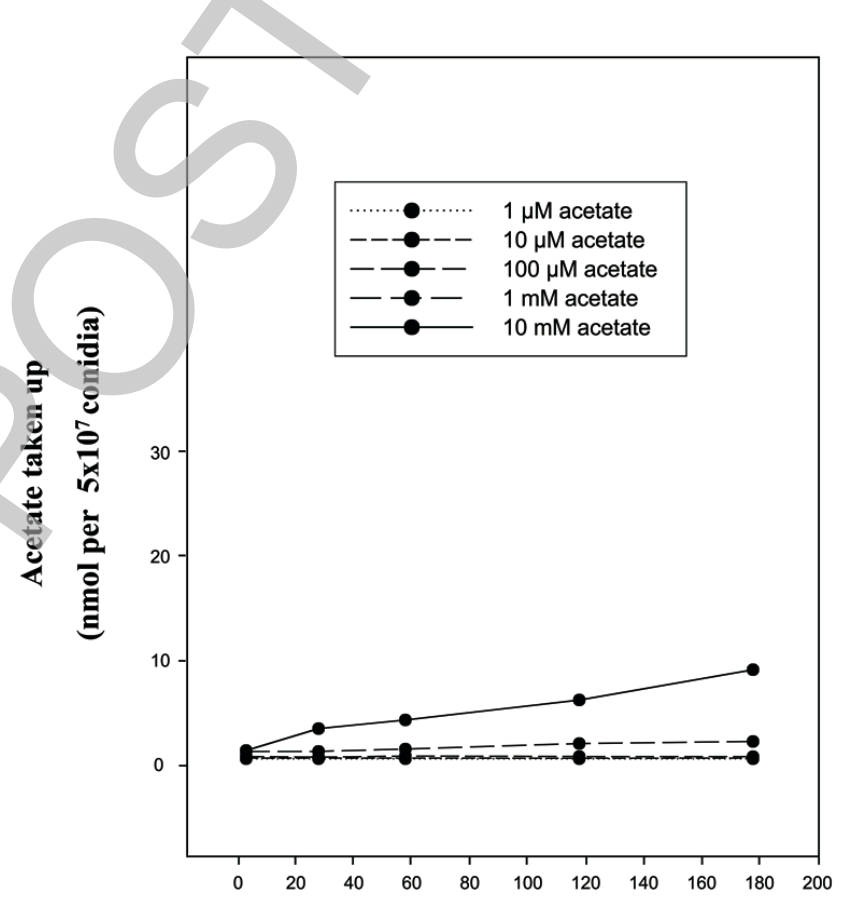

Time (seconds) 
FIGURE 8

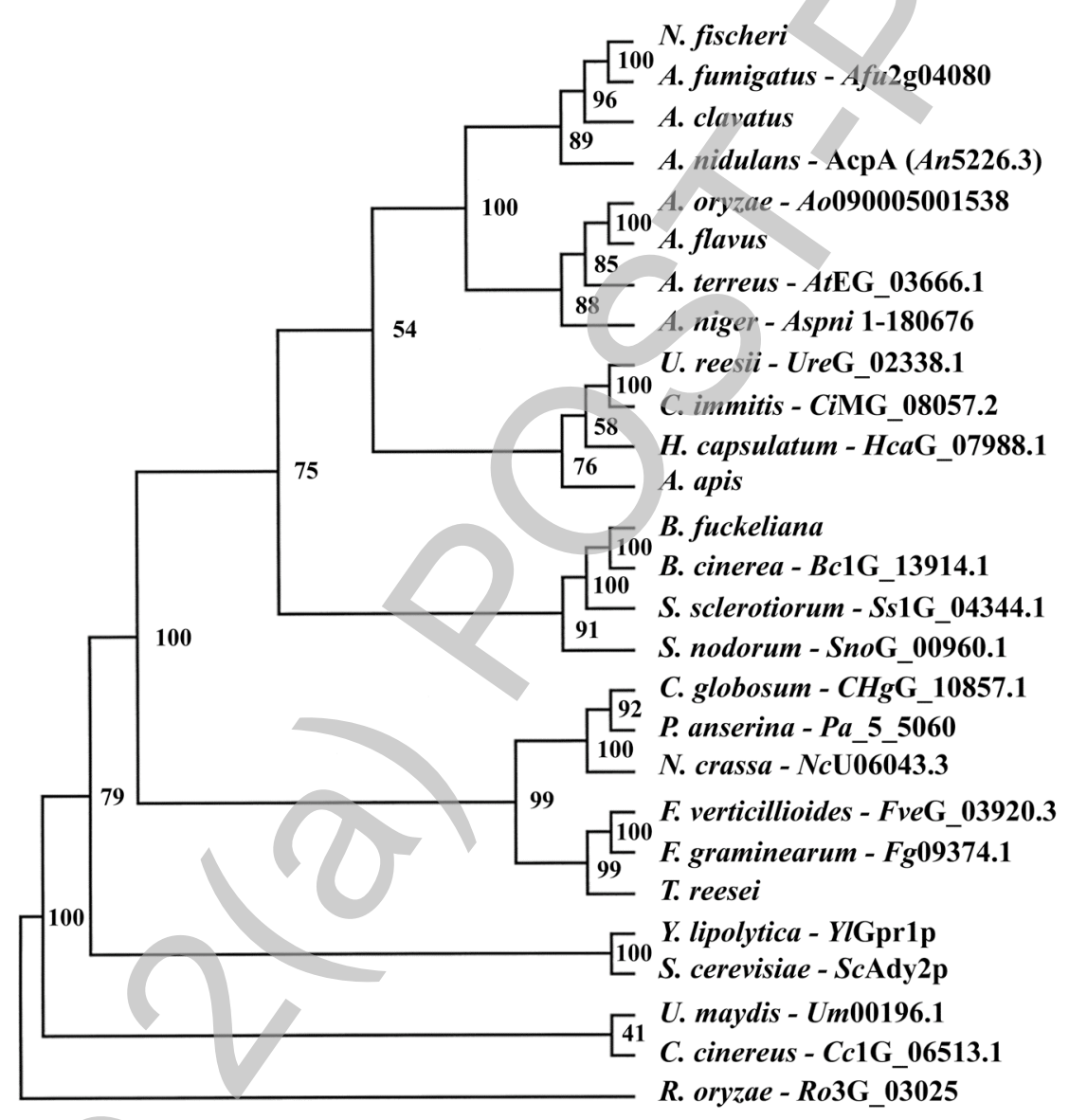

Licenced copy. Copying is not permitted, except with prior permission and as allowed by law. (C) 2008 The Authors Journal compilation (c) 2008 Biochemical Society 